\title{
Development and Optimization of Capecitabine loaded Nanoliposomal System for Cancer Delivery
}

\author{
Sandip Mohan Honmane ${ }^{1}$, Sagar Maruti Chimane ${ }^{2}$, Sandip Akaram Bandgar ${ }^{2, \star}$, Shitalkumar \\ Shivagonda Patil ${ }^{2}$
}

${ }^{1}$ Department of Pharmaceutics, Annasaheb Dange College of B. Pharmacy, Ashta, Shivaji University, Kolhapur, Maharashtra, INDIA. ${ }^{2}$ Department of Pharmaceutics, Ashokrao Mane College of Pharmacy, Peth-Vadgaon, Shivaji University, Kolhapur, Maharashtra, INDIA.

\begin{abstract}
Objectives: The Main objective of this study was to develop and optimize Capecitabine loaded nanoliposomes for prolonged drug delivery in cancer treatment. Methods: Liposomes were prepared by the thin film hydration method followed by sonication. The parameters affecting the vesicle size and percentage drug entrapment of liposome are amount of soyaphosphatidyl choline and cholesterol used in their preparation. The Capecitabine liposomal formulation was optimized using $3^{2}$ factorial design in this amount of soya Phosphatidylcholine and cholesterol were selected as two independent variables to obtain stable liposome with small vesicle size and maximum entrapment efficiency. Results: Compatibility studies were carried out by using FT-IR and DSC, the results showed that there was no significant interaction between drug and excipients. The formulated liposomal prepartions were evaluated for various parameters and results were obtained for optimized batch (B3) Showed vesicle size $178.9 \mathrm{~nm}$, zeta potential $-77.9 \mathrm{mV}$ to $-82.7 \mathrm{mV}$, entrapment efficiency $79.65 \%$ and percentage drug release $92.07 \%$ up to $12 \mathrm{~h}$. Conclusion: Liposomal drug delivery is targeted as to provide more drug concentration at the site of action and with a sustainable drug release followed Higuchi-matrix model. Ultimately, reducing the dosing frequency with minimizing the side effects related to high drug intake. Liposome has been provided a spectrum of options and opportunities for designing and practicing site specific, targeted drug therapy.
\end{abstract}

Key words: Capecitabine, Liposome, $3^{2}$ Factorial design, Percent drug entrapment, Release kinetics.

\section{INTRODUCTION}

Nowadays cancer is the main cause of death in human beings after cardiovascular disease. The most common forms of cancer are breast, prostate, colon and lung cancers. Presently chemotherapy, hormonal, gene, surgery and radiation therapies are used to treat cancer. But chemotherapeutic agents are commonly preferred to treat cancer. However, due to high doses of these drugs cause toxic effects. Most common side effects like gastrointestinal problems and systemic side effects will appear in anticancer therapy. ${ }^{1}$ Successfully translating anticancer nano medicines to demonstration of therapeutic value in the clinic is challenging. Despite liposomes have been proven to be an ideal drug carrier that has a strong impact on the pharmacokinetics and tissue distribution of incorporated drugs, resulting in enhanced efficacy as well as greatly reduced systematic toxicity of drugs. Liposome have gained attention as a carrier system for a therapeutically active agent, owing to their unique characteristics, biocompatible, biodegradable, low toxicity, lack of opsonization and improves the pharmacokinetics and pharmacodynamics profile of therapeutic agent. ${ }^{2}$ Structurally, liposomes are concentric bilayer vesicles of natural or synthetic phospholipid. ${ }^{3,4}$ Due to their hydrophobic, hydrophilic and small size; liposomes are promising systems for drug
Submission Date: 30-08-2019; Revision Date: 18-11-2019; Accepted Date: 04-02-2020

DOI: 10.5530/ijper.54.2.43 Correspondence: Mr. Sandip Akaram Bandgar

Department of Pharmaceutics, Ashokrao Mane College of Pharmacy, Peth-Vadgaon, Shivaji University, Kolhapur416112, Maharashtra, INDIA Phone: +91-8600009719 E-mail: sandiphonmane@ gmail.com

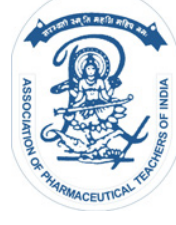

www.ijper.org 
delivery. ${ }^{5,6}$ Lipid composition, surface charge, size and preparation method considerably change the properties of liposome. ${ }^{7,8}$ Furthermore, composition of bilayer notably marks the 'rigidity' and charge of liposomal formulation. ${ }^{9}{ }^{10}$ From the experimental findings of various studies it was observed that the variations in liposomal size, can affect the circulation time in plasma. The vesicle size range from 80 to $200 \mathrm{~nm}$ is nowadays considered to combine satisfactory reservoir capacities without sacrificing bioavailability. ${ }^{11}$ Capecitabine is a fluoropyrimidine carbamate with antineoplastic activity, commonly used to treat metastatic breast cancer, colorectal cancer and quickly absorbed from the GI tract. ${ }^{12}$ Capecitabine is a prodrug that is selectively tumour-activated to its cytotoxic moiety, fluorouracil, by thymidine phosphorylase. Fluorouracil is further metabolized to two active metabolites, 5-fluoro-2'-deoxyuridine 5'-monophosphate (FdUMP) and 5-fluorouridine triphosphate (FUTP), within normal and tumour cells. These metabolites cause cell injury by two different mechanisms. First, FdUMP and the folate cofactor, N5-10-methylenetetrahydrofolate, bind to thymidylate synthase (TS) to form a covalently bound ternary complex. This binding inhibits the formation of thymidylate from 2'-deaxyuridylate. Thymidylate is the necessary precursor of thymidine triphosphate, which is essential for the synthesis of DNA, therefore a deficiency of this compound can inhibit cell division. Secondly, nuclear transcriptional enzymes can mistakenly incorporate FUTP in place of uridine triphosphate (UTP) during the synthesis of RNA. This metabolic error can interfere with RNA processing and protein synthesis through the production of fraudulent RNA. The recommended daily oral dose is $2500 \mathrm{mg} / \mathrm{m}^{2}$ for 2 weeks, followed by a 1 -week rest period, given in 3 week cycles which is high and it has a short elimination half-life of 0.55-0.89 h.

Most significant problems related with Capecitabine are a short half-life and its rapid metabolism in the liver.
Thus, high doses of Capecitabine is preferred in current clinical treatment cause some undesirable side effects. Hence, there is a need to develop a prolonged release type of Capecitabine formulation. . $^{3-15}$

The objective of present investigation was to prepare and optimize Capecitabine loaded nanoliposomes for prolonged drug delivery in cancer therapy.

\section{MATERIALS AND METHODS}

\section{Materials}

Capecitabine was received as gift sample from Acebright (India) Pharma Pvt. Ltd. Bengaluru, Karnataka, India. Soya Lecithin was procured as gift sample from lipoid GmbH, Germany. Cholesterol, Chloroform and Methanol were purchased from Molychem, Mumbai, Maharashtra, India. All other materials were used of analytical grade.

\section{Preparation of liposomes}

Liposomes were prepared by the thin film hydration technique. Soya phosphatidylcholine and Cholesterol were taken in various weight ratios and dissolved in chloroform to the get concentration of lipid phase $60 \mathrm{mg} /$ $\mathrm{mL}$ in a rotary flask. The film was formed by attaching flask to a rotary evaporator at $40^{\circ} \mathrm{C}$ temperature, rotated at $50 \mathrm{rpm}$; under vacuum for $1 \mathrm{~h} .{ }^{16}$ The composition of liposomal formulation was shown in Table 1. Formed film was hydrated by using a phosphate buffer solution ( $\mathrm{pH}$ 7.4) containing Capecitabine $(1 \mathrm{mg} / \mathrm{mL})$, followed by hand shaking for 10 min to produce a liposomes having lipid concentration $10 \mathrm{mg} / \mathrm{mL}$. To get small and uniformed size vesicles, liposomal preparations were kept for sonication for 20 min cycle at $20 \mathrm{sec}$ working and 10 sec rest at a $30-\mathrm{kHz}$ low frequency ultrasonic at temperature $37^{\circ} \mathrm{C} .{ }^{17}$ The formed liposomes were kept undisturbed at room temperature for 1-2 $\mathrm{h}$. Then followed by storage at $4^{\circ} \mathrm{C}$ in an inert atmosphere for $24 \mathrm{hr}$ to

\begin{tabular}{|c|c|c|c|c|}
\hline \multicolumn{4}{|c|}{ Table 1: Optimization of Capecitabine loaded liposomal formulation. } \\
\hline $\begin{array}{c}\text { Formulation } \\
\text { code }\end{array}$ & SPC:CH Ratio (mg) & $\begin{array}{c}\text { Drug } \\
\text { (mg) }\end{array}$ & $\begin{array}{c}\text { Chloroform } \\
(\mathbf{m L})\end{array}$ & $\begin{array}{c}\text { Methanol } \\
\text { (mL) }\end{array}$ \\
\hline B1 & $60(-1): 10(-1)$ & 10 & 6 & 3 \\
\hline B2 & $90(0): 10(-1)$ & 10 & 6 & 3 \\
\hline B3 & $120(+1): 10(-1)$ & 10 & 6 & 3 \\
\hline B4 & $60(-1): 20(0)$ & 10 & 6 & 3 \\
\hline B5 & $90(0): 20(0)$ & 10 & 6 & 3 \\
\hline B6 & $120(+1): 20(0)$ & 10 & 6 & 3 \\
\hline B7 & $60(-1): 30(+1)$ & 10 & 6 & 3 \\
\hline B8 & $90(0): 30(+1)$ & 10 & 6 & 3 \\
\hline B9 & $120(+1): 30(+1)$ & 10 & 6 & 3 \\
\hline
\end{tabular}


complete vesicle formation. Final liposomal dispersion was filled in to sterile glass vials for further process. ${ }^{18}$

\section{Optimization of Liposome Preparation}

\section{Full factorial design}

Optimization of Capecitabine loaded liposome was done by using $3^{2}$ factorial design. In this design, amount of phospholipid (SPC) (X1) and amount of $\mathrm{CH}$ (X2) were evaluated as independent variables. Formulated 9 possible combinations using $3^{2}$ factorial design by taking each independent variable at 3 different levels as shown in Table 1. Evaluated fixed responses vesicle size and \% drug entrapment as Y1 and Y2 respectively.

\section{Speed of the rotary evaporator}

It is desirable to obtain a thin and uniform film as it governs the final output of liposomal preparation. The speed of rotation was varied from $60 \mathrm{rpm}$ to $100 \mathrm{rpm}$ during film formation as well as during hydration.

\section{The ratio and volume of solvent system}

The solvent system was optimized by taking various combinations of organic solvents that is chloroform and methanol. The ratios 3:1, 3:2 and 3:3 were tried and the film was evaluated in terms of its uniformity.

\section{$\mathrm{pH}$ of the hydrating media}

The effect of $\mathrm{pH}$ of the phosphate buffer was studied on the formulation. $\mathrm{pH}$ affects the entrapment of the drug in the liposomes. $\mathrm{pH}$ of hydrating buffer was adjusted at values closer to the pKa of the drug and entrapment efficiency was estimated. Methanol and phosphate buffer $\mathrm{pH}$ 5.2, 6.8 and 7.4 were used as hydrating media and formulations were studied in terms of entrapment efficiency.

\section{Compatibility studies by FTIR}

FT-IR spectra of pure drug and physical mixture was recorded by FT-IR spectrophotometer (Agilent technologies, carry 630 FTIR) using potassium bromide $(\mathrm{KBr})$ disk technique. $\mathrm{KBr}$ disk of the Capecitabine and physical mixture was prepared and analyzed at the wavelength range of 4000 to $400 \mathrm{~cm}^{-1}$. ${ }^{19}$

\section{Differential Scanning Calorimetry}

DSC studies of pure Capecitabine and physical mixture with polymers were carried out to check compatibility between them on Mettler -Toledo DSC 821e instrument. Calibration of temperature and enthalpy scale was done by using indium and zinc standards. Samples were sealed hermetically in aluminium containers and heated over a temperature range of $25-250^{\circ} \mathrm{C}$ at $10^{\circ} \mathrm{C} /$ min constant rate. Nitrogen gas was used to create inert atmosphere at flow rate of $50 \mathrm{~mL} / \mathrm{min}^{19,20}$

\section{Evaluation of Capecitabine Loaded Liposome Particle size}

Size distribution and mean vesicle size of Capecitabine loaded liposome was determined using (HORIBA scientific SZ-100) works on mechanism of photon correlation spectroscopy. Size analysis was done at room temperature for $100 \mathrm{sec}$ and $90^{\circ}$ as angle of detection. ${ }^{21}$

\section{Zeta potential}

Charge on Capecitabine loaded liposome surface was determined using Zetasizer, (HORIBA scientific SZ-100). All formulations were diluted in deionized water $(1 / 10, \mathrm{w} / \mathrm{v})$ and placed in measurement cell for analysis. Average zeta potential and charge on the liposomes was determined by keeping sample for $60 \mathrm{sec}^{21}$

\section{Entrapment efficiency}

To calculate actual drug loading in liposome, $5 \mathrm{~mL}$ of drug loaded liposomal preparation was dispersed in 5 $\mathrm{mL}$ of ethanol to rupture liposome and then centrifuged at $9500 \mathrm{rpm}$, at $1{ }^{\circ} \mathrm{C}$ temperature for 45 min using cooling centrifuge (REMI C30, Mumbai). Supernatant was separated carefully and suitably diluted with $10 \mathrm{~mL}$ of phosphate buffer solution $\mathrm{pH}$ 7.4. Diluted dispersion was filtered through a microsyringe filter $(0.2 \mu \mathrm{m})$ and recorded absorbance of filtrate at $304 \mathrm{~nm}$ with UV/ Visible spectrophotometer (Shimadzu, Japan). The total amount of drug present in the formulation was determined by suspending $5 \mathrm{~mL}$ of liposomes in $5 \mathrm{~mL}$ of ethanol to destroy the liposomal structure. The formed pellet was washed with $1 \mathrm{~mL}$ phosphate buffer solution $\mathrm{pH} 7.4$ and vortexes, in order to remove the free drug adsorbed on the surface of liposomes. Formed dispersion diluted with $10 \mathrm{ml}$ of phosphate buffer solution $\mathrm{pH} 7.4$ and filtered through a microsyringe filter $(0.2 \mu \mathrm{m})$. Analyzed the filtrate for Capecitabine by measuring the absorbance at $304 \mathrm{~nm}$ using UV/Visible spectrophotometer. The entrapment efficiency was calculated by using a formula,

Entrapment efficiency $=\frac{\mathrm{A}-\mathrm{B}}{\mathrm{A}} \times 100$

Where ' $\mathrm{A}$ ' is total amount of drug that is detected both in the supernatant layer and resident layer and ' $\mathrm{B}$ ' is the amount of drug detected only in the supernatant. ${ }^{22}$

\section{Transmission Electron Microscopy}

The structural appearance of Capecitabine liposomes was analysed by TEM photographs (using Hitachi S-7500). The TEM images were taken at 30,000× magnification and $100 \mathrm{kV}$ by putting drop of diluted lipo- 
somal dispersion on a 200-mesh carbon coated copper grid. $^{23}$

\section{In-vitro drug release study}

In-vitro drug release studies of all batches of liposomes were carried out with the help of modified USP XXI dissolution model using glass tube opened from both the ends. The tube was tied at one end with treated cellophane membrane (molecular weight cut off [MWCO] $10 \mathrm{kDa}$, Thermo Fisher Scientific) and dipped into the $250 \mathrm{~mL}$ beaker containing $200 \mathrm{~mL}$ of water / ethanol mixture (70:30) as a dissolution medium and temperature was maintained at $37 \pm 1^{\circ} \mathrm{C}$. Liposomal preparation $(10 \mathrm{~mL})$ was added in the tube and the dissolution medium stirred using a magnetic stirrer at $100 \mathrm{rpm} .^{24}$ Withdrawn $2 \mathrm{~mL}$ samples from the receiver compartment at different time intervals up to $12 \mathrm{~h}$ and placed with equal volumes of fresh dissolution medium and spectrometrically assayed for drug content at $304 \mathrm{~nm}$ using UV-Visible spectrophotometer. All readings were taken in triplicates. ${ }^{25,26}$

\section{Kinetic Modeling of Release Profiles}

The results of drug release from liposomal formulations were correlated to kinetic models like zero order, first order, Higuchi matrix, Korsmeyer-Peppas, HixsonCrowell. The best model was considered based on the maximum correlation coefficient value. ${ }^{27,28}$

\section{Stability of Liposomes}

The physical stability of drug loaded liposomal formulation was carried out by observing physical appearance, change in vesicle size distribution and mean vesicle size with time. Formulation $(5 \mathrm{~mL})$ was stored at refrigerated $\left(4^{\circ} \mathrm{C} \pm 2^{\circ} \mathrm{C}\right)$, room temperature $\left(24^{\circ} \mathrm{C}\right)$ and physiologic temperature $\left(37^{\circ} \mathrm{C}\right)$, conditions as per ICH guidelines. The samples were taken at specific time intervals of 1 , 2 and 3 months and evaluated for physical appearance, mean vesicle size, size distribution and percent drug entrapment as same above description. ${ }^{29}$

\section{RESULTS AND DISCUSSION \\ Compatibility studies}

The compatibility of the drug with other excipients was determined using FTIR studies. Infra-red spectrum of pure drug and physical mixture of drug with excipients were recorded over $\mathrm{KBr}$ disc method and obtained spectra were shown in the Figure 1. The FTIR spectrum of the pure drug Capecitabine $\mathrm{HCl}$ showed absorption bands of Carboxylic acid $(\mathrm{C}=\mathrm{O})$ at $1707 \mathrm{~cm}^{-1}$, Alkanes $(\mathrm{C}-\mathrm{H})$ at $2920 \mathrm{~cm}^{-1}$, aromatic $\mathrm{C}=\mathrm{C}$ at $1602.85 \mathrm{~cm}^{-1}$. There was no appearance or disappearance of peaks

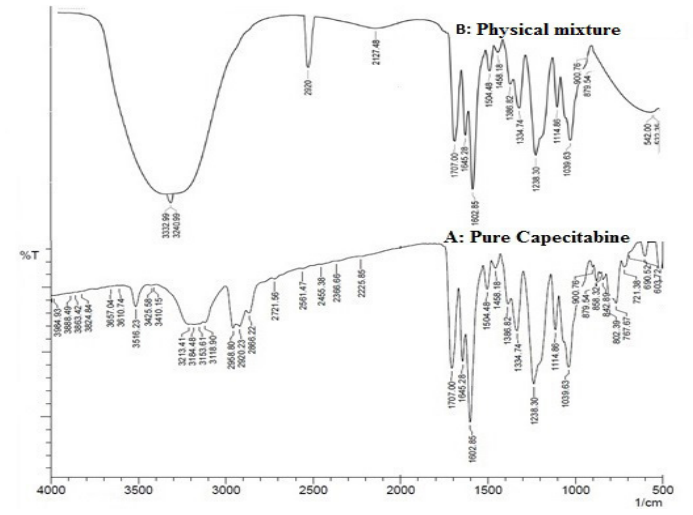

Figure 1: FTIR spectra of Pure Capecitabine and physical mixture.

in the physical mixture of drug and excipient, hence it confirm the absence of any chemical interaction between the drug and other excipients (similar observations reported by Venugopalarao $G$ et al. in 2015).

\section{Differential scanning colorimetry}

The thermal behavior of pure Capecitabine and physical mixture of drug with cholesterol and phosphatidyl choline were determined using DSC studies and results were showed in Figure 8. DSC of pure capecitabine shows a sharp endothermic peak at $121^{\circ} \mathrm{C}$ recognized to melting of pure capecitabine during DSC run. The DSC thermal profile of drug when mixed with cholesterol and phosphatidylcholine shows that there was a negligible shift in the peak $\left(118^{\circ} \mathrm{C}\right)$ and confirms that there were no interactions between the drug and the polymers similar observations reported by Venugopalarao $G$ et al. in 2015).

\section{Optimization of formulation}

Saturated phospholipids (SPC) have advantages over unsaturated phospholipids in the form of stability and biocompatibility. Based on preliminary studies, concentrations of soyaphosphatidyl choline and cholesterol were selected to get stable liposomes free from of any aggregation, fusion, having small vesicle size and more percent drug entrapment. This finding indicates that amount of soya phosphatidyl choline and cholesterol is a more prominent factor for formation of liposomes. Optimized concentrations of soyaphosphatidyl choline (60-120mg) and cholesterol (10-30 mg) were sufficient to produce liposomes free from aggregation and sedimentation with small vesicle size and good drug entrapment.

\section{Particle size and particle size distribution}

The drug loaded liposomes of the different formulations containing 60-120 mg soya phosphatidylcholine and 10-30 $\mathrm{mg}$ cholesterol was found the mean vesicle 
size of in the range of $178.8-378.3 \mathrm{~nm}$. The polydispersity index of $0.29-0.40$ for drug loaded liposomes indicated narrow vesicle size distribution (Table 2). All the formulation of liposomes exhibited a relatively narrow range of size distribution. The concentration of soya phosphatidyl choline and cholesterol was directly proportional to the vesicle size of drug loaded formulations. The cholesterol increases the rigidity of the membrane than the lipid concentration in liposomal dispersion. A typical particle size distribution profile observed for prepared liposomes is shown in Figure 2, 3.

\section{Percentage Drug Entrapment}

PDE is expressed as the amount of the drug included into liposomes virtual to the total amount of drug used. Percent drug entrapment for all the formulations was observed in the range of $18.16 \%-79.86 \%$. Optimization of concentrations of soya phosphatidyl choline and cholesterol for liposomal formulation was performed by considering parameters viz., vesicle size and entrapment efficiency of the liposomes as these parameters mainly affect the deposition of the drug. Based on drug entrapment and low vesicle size, formulation code B3 was found to be significant.

\section{Full factorial design}

The effect of independent variables SPC and $\mathrm{CH}$ was analyzed by response surface plots using DESIGN EXPERT $^{(B)}$ (version 7.0) software. Figure 4 shows responses for liposomal vesicle size (Y1) and \% entrapment efficiency (Y2) by the effects of independent variables. Observed coefficient values for the drug loaded liposomes are represented in Eq.(1). and Eq.(2).

$\mathrm{Y}_{1}=343+17.8 \mathrm{X}_{1}+53.18 \mathrm{X}_{2}+25.87 \mathrm{X}_{1} \mathrm{X}_{2}-28.35 \mathrm{X}_{1}{ }^{2}-30.25 \mathrm{X}_{2}{ }^{2}$

$Y_{2}=45.44+17.10 X_{1}-8.77 X_{2}-10.89 X_{1} X_{2}$

From the above generated surface response plots and regression equations it is manifest that the SPC and $\mathrm{CH}$ at different concentrations produce positive correlation

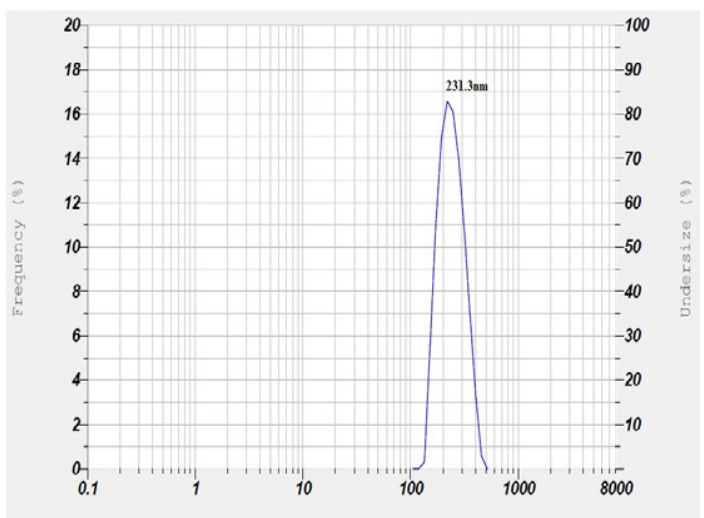

Figure 2: Particle size distribution in liposomes without sonication (B3). with respect to vesicle size of capecitabine loaded liposomes. The size enlargement was the consequence of an increase in lipid concentration into liposomal bilayer while cholesterol gives stiffness to bilayer membrane. Results of determination coefficient $\left(R^{2}=0.9473\right.$ and 0.9089 for $Y_{1}$ and $Y_{2}$ respectively) and adjusted determination coefficient $\left(R^{2}=0.8594\right.$ and 0.8542 for $Y_{1}$ and $Y_{2}$ respectively), it was found comparable and indicated a high significance of the model. The " $p$ " values for vesicle size and $\% \mathrm{EE}$ were found to be 0.0049 and 0.039 respectively, this values of $p<0.05$ (Prob $>$ F) implies that the model terms are significant by rejection of null hypothesis.

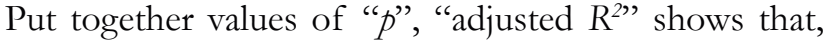
significant synergistic interaction between independent variables for $3^{2}$ factorial design model at $P<0.05$.

\section{Zeta Potential determination}

Measurement of the zeta potential of liposomes gives an indication of particle charge and dispersion stability. The zeta potential of the optimized formulation (B3) was found to be $-77.9 \mathrm{mV}$ to $-82.7 \mathrm{mV}$ (Figure 5,6 ), indicating the sufficient charge and mobility to inhibit aggregation of vesicles.

\section{Transmission Electron Microscopy}

The shape and appearance of Capecitabine loaded liposomes was analyzed using TEM studies. The TEM image of optimized batch B3 shows smooth spherical shape liposome with small vesicle size shown in Figure 7. This supports the results of particle size.

\section{In-vitro drug release studies}

Depending on the concentration of phospholipid and cholesterol variable drug release profiles was successfully tailored. All the formulations showed release up to $12 \mathrm{hr}$ and except B2 formulation, all other formulation exhibits more than $90 \%$ of drug release. Formulation

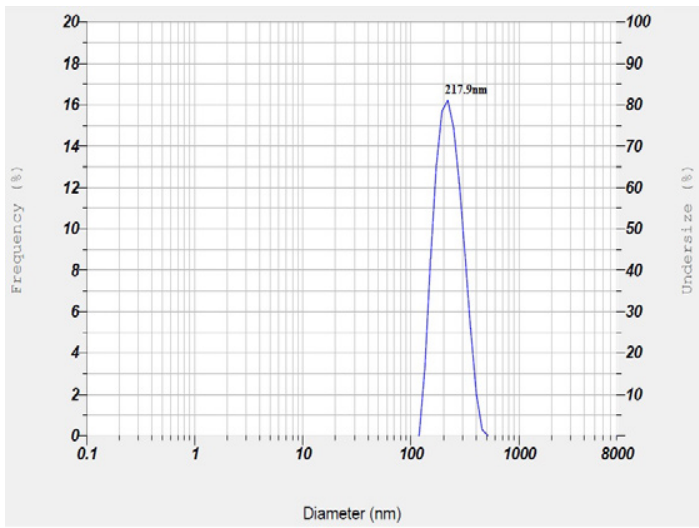

Figure 3: Particle size distribution of sonicated liposome (B3). 
B9 $(94.09 \%)$ show maximum release compared to other formulations shown in Figure 9.

\section{Release Kinetic}

To know the mechanism of drug release, all data obtained from the in vitro drug release studies of developing liposomes were fitted in kinetic models. The
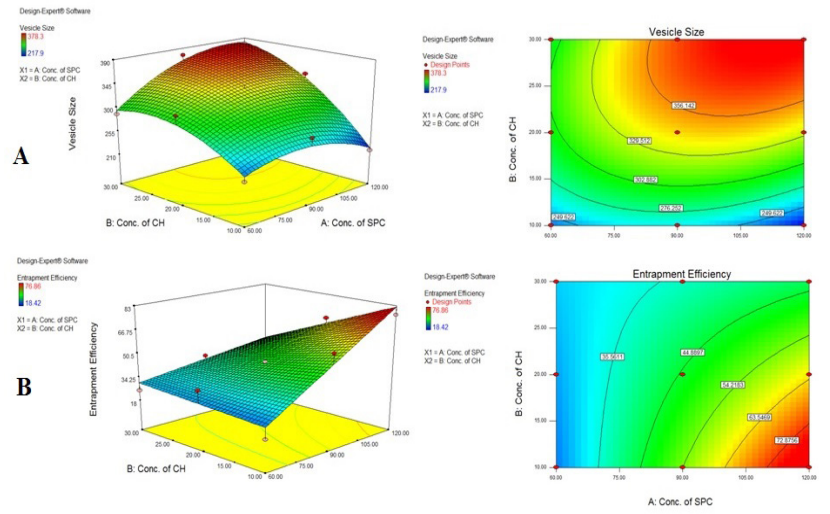

Figure 4: 3D response surface plot depicting effect of independent variables on (A) vesicle size, (B) percent drug entrapment (PDE) of Capecitabine loaded liposomes.

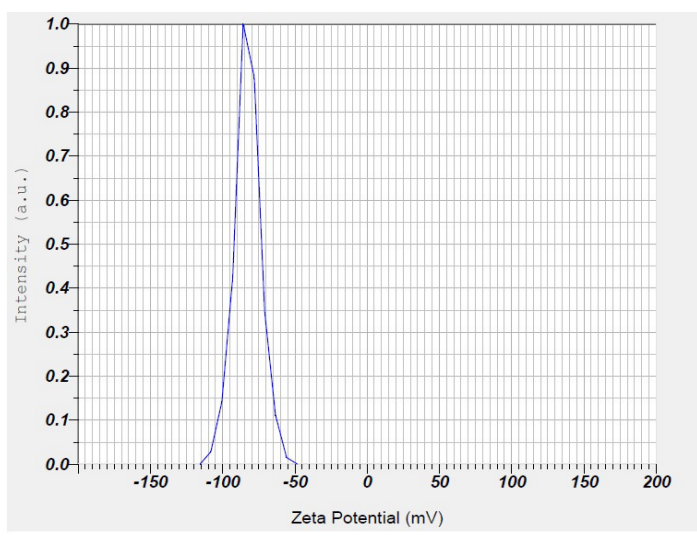

Figure 5: Zeta potential in liposomal formulation without sonication (B3). correlation coefficient $\left(R^{2}\right)$ was used as a tool for best fitting, regression values for formulation were between $\left(R^{2}\right)=0.834$ to 0.998 . From the regression values of different models for all the formulations, observed the in vitro release of capecitabine from nanoliposomes was best fitted in the Higuchi matrix kinetic model except

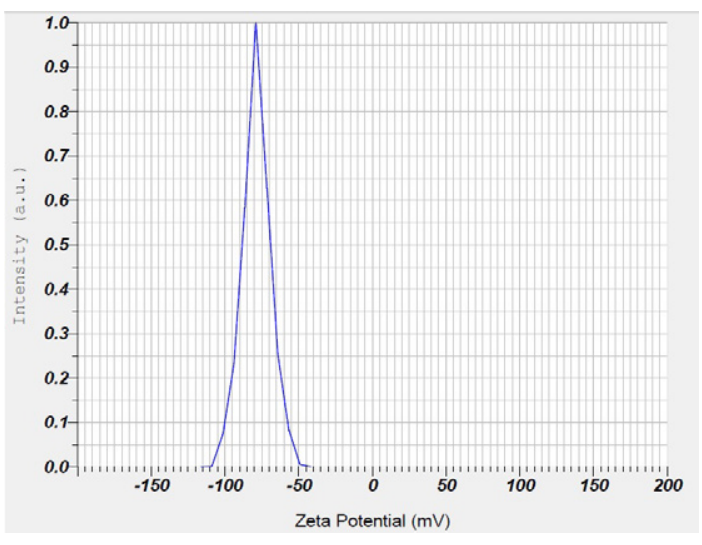

Figure 6: Zeta potential in batch of sonicated liposomes (B3).

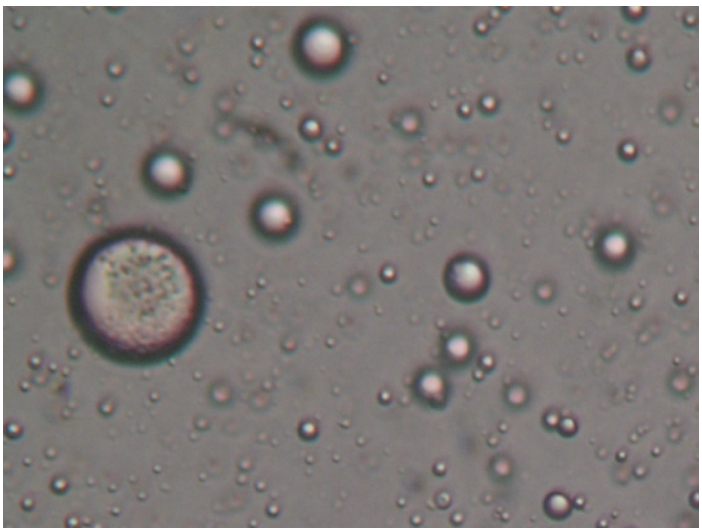

Figure 7: TEM micrograph of Capecitabineloaded liposome (B3).

Table 2: Vesicle size and percent drug entrapment of different batches of liposomal preparation.

\begin{tabular}{|c|c|c|c|c|}
\hline Formulation codes & \multicolumn{2}{|c|}{ Vesicle size (nm) } & \multicolumn{2}{c|}{ Percentage Drug Entrapment (PDE) } \\
\hline & Thin film hydration & Sonication & Thin film hydration* & Sonication* \\
\hline B1 & 232.2 & 198.08 & $18.42 \pm 0.932$ & $25.05 \pm 0.013$ \\
\hline B2 & 274.5 & 230.51 & $61.37 \pm 1.052$ & $58.05 \pm 0.048$ \\
\hline B3 & 231.3 & 217.9 & $79.86 \pm 0.523$ & $72.36 \pm 0.001$ \\
\hline B4 & 314.4 & 298.10 & $36.98 \pm 0.639$ & $33.28 \pm 0.011$ \\
\hline B5 & 319.4 & 331.09 & $45.12 \pm 1.212$ & $49.71 \pm 0.193$ \\
\hline B6 & 340.2 & 204.04 & $66.24 \pm 1.231$ & $61.62 \pm 0.062$ \\
\hline B7 & 288.2 & 231.09 & $25.16 \pm 1.126$ & $41.24 \pm 0.096$ \\
\hline B8 & 376.3 & 274.91 & $38.79 \pm 0.732$ & $51.83 \pm 0.359$ \\
\hline B9 & 378.3 & 374.11 & $40.05 \pm 0.562$ & $36.89 \pm 0.791$ \\
\hline
\end{tabular}

*Each value represent Mean $\pm S D, n=3$. 
formulation code B7 and B9. Exponent values (n) in Korsmeyer-Peppas equation for all formulations under the study condition were less than 0.5. All the formulations showed Fickian release mechanism i.e. release due to diffusion of drug from matrix except formulation B7 and B9 (Table 3).

In vitro drug release of capecitabine liposomes followed zero order kinetics for B9 and Hixson-Crowell kinetics for $\mathrm{B} 7$ formulation. Zero order release pattern indicated the release of drug independent of its initial concentration. Hixson Crowell model suggests the release of drug in the planes. This may have occurred due to adsorption of capecitabine on the surface of liposomes.

\section{Stability study}

The physical appearance of liposomal formulation (B3) stored at $4^{\circ} \mathrm{C}, 24^{\circ} \mathrm{C}$, and $37^{\circ} \mathrm{C}$ was evaluated at 1,2 , and 3 months of intervals. The liposomal formulation (B3) stored at $4^{\circ} \mathrm{C}$ and $24^{\circ} \mathrm{C}$ was found stable except stored at $37^{\circ} \mathrm{C}$.

The mean particle size and percent entrapment of formulation were evaluated as a function of temperature. There is no significant change in mean particle size of the liposome stored at $4^{\circ} \mathrm{C}$ and $24^{\circ} \mathrm{C}$ except for storing at $37^{\circ} \mathrm{C}$ (Table 4).

\begin{tabular}{|c|c|c|c|c|c|c|}
\hline \multirow[t]{2}{*}{ Formulation codes } & \multirow[t]{2}{*}{ Zero order $\left(R^{2}\right)$} & \multirow[t]{2}{*}{ First order $\left(R^{2}\right)$} & \multirow{2}{*}{$\begin{array}{c}\text { Higuchi } \\
\qquad\left(R^{2}\right)\end{array}$} & \multirow[t]{2}{*}{ Hixon crowell $\left(R^{2}\right)$} & \multicolumn{2}{|c|}{ Korsmeyer-peppas } \\
\hline & & & & & $\left(R^{2}\right)$ & $\mathbf{n}$ \\
\hline B1 & 0.987 & 0.974 & 0.993 & 0.992 & 0.983 & 0.458 \\
\hline B2 & 0.984 & 0.983 & 0.992 & 0.991 & 0.989 & 0.484 \\
\hline B3 & 0.991 & 0.971 & 0.993 & 0.991 & 0.988 & 0.469 \\
\hline B4 & 0.988 & 0.965 & 0.991 & 0.985 & 0.989 & 0.403 \\
\hline B5 & 0.977 & 0.990 & 0.998 & 0.996 & 0.988 & 0.438 \\
\hline B6 & 0.989 & 0.983 & 0.998 & 0.988 & 0.980 & 0.437 \\
\hline B7 & 0.970 & 0.975 & 0.988 & 0.993 & 0.957 & 0.408 \\
\hline B8 & 0.975 & 0.947 & 0.986 & 0.985 & 0.957 & 0.420 \\
\hline B9 & 0.990 & 0.986 & 0.989 & 0.978 & 0.973 & 0.437 \\
\hline
\end{tabular}

\section{Table 4: The mean particle size and percent drug entrapment (PDE) of formulation (B3) stored at different tem-} perature conditions.

\begin{tabular}{|c|c|c|c|c|c|c|}
\hline Storage temperature & \multicolumn{2}{|c|}{$4^{\circ} \mathrm{C}$} & \multicolumn{2}{|c|}{$24^{\circ} \mathrm{C}$} & \multicolumn{2}{|c|}{$37^{\circ} \mathrm{C}$} \\
\hline Parameter & Vesicle size & PDE* $^{*}$ & Vesicle size & PDE* $^{*}$ & Vesicle size & PDE* \\
\hline Initial & 217.9 & $79.86 \pm 0.523$ & 217.9 & $79.86 \pm 0.523$ & 217.9 & $79.86 \pm 0.523$ \\
\hline 1 Month & 218.2 & $79.20 \pm 0.221$ & 220.3 & $78.42 \pm 0.233$ & 224.1 & $77.26 \pm 0.182$ \\
\hline 2 Month & 222.1 & $78.32 \pm 0.131$ & 228.2 & $77.63 \pm 0.342$ & 234.1 & $76.41 \pm 0.526$ \\
\hline 3 Month & 224.3 & $78.77 \pm 0.422$ & 232.3 & $77.44 \pm 0.131$ & 242.1 & $74.12 \pm 0.423$ \\
\hline
\end{tabular}

*Each value represent Mean \pm SD, $n=3$.

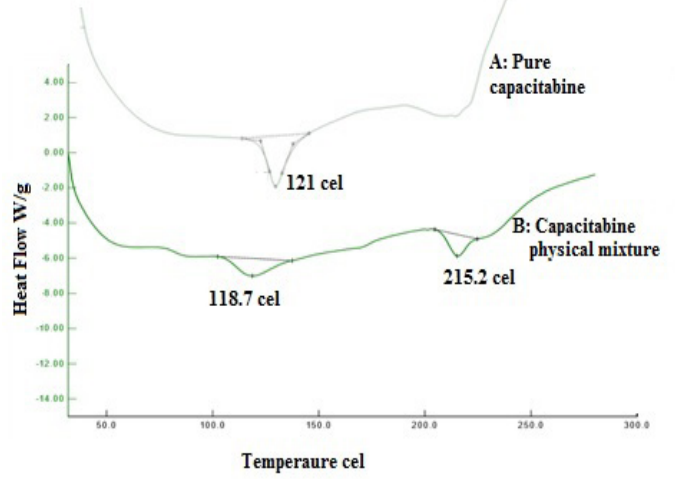

Figure 8: DSC thermogram of pure drug Capecitabine and Physical mixture.

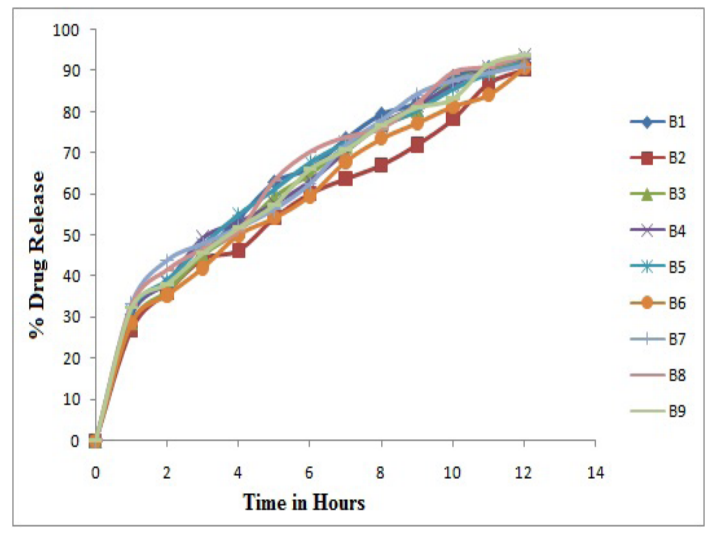

Figure 9: Drug Release profile of Capecitabine loaded liposomes. 


\section{CONCLUSION}

In the present investigation, we have developed a method to encapsulate water soluble anticancer agent (capecitabine) into the stable nanoliposomal formulation to enhance tumor target and reduce unwanted side effects of drug on normal tissues. The physicochemical properties of the liposomes, like vesicle size, zeta potential and entrapment efficiency were optimized, so that they could remain constant during the long-term storage period in the refrigerator and incubation at $37^{\circ} \mathrm{C}$. In this execution, various compositions of lipid (Soya phosphatidyl choline) and cholesterol were tested to get nanosized liposomes with prolonged drug release at the site of action. Surface response plots and regression equations manifest that the SPC and $\mathrm{CH}$ at different concentrations produce positive correlation with respect to vesicle size of capecitabine loaded liposomes. The size enlargement was the consequence of an increase in lipid concentration into liposomal bilayer while cholesterol gives stiffness to bilayer membrane.

In vitro drug release and drug release kinetics studies of capecitabine liposomes showed drug release by a diffusion mechanism followed by the Higuchi matrix model over the long period of time. Stability studies reveal that liposomal formulation stable in refrigerated storage $\left(4^{\circ} \mathrm{C}\right)$ condition. Therefore, the nanoliposomal formulation of capecitabine may reduce the dosing frequency and targeted at the site of action, ultimately it will reduce the side effect associated with high dose and non-targeted delivery of capecitabine. Further in-vivo bioavailability studies can be carried for these formulations to make promising drug delivery system and investigating pharmacokinetics and pharmacodynamics parameters.

\section{ACKNOWLEDGEMENT}

The authors are thankful to lipoid GmbH, Germany for providing gift sample of phospholipid. Also thankful to the Principal and Management of the Annasaheb Dange College of Pharmacy, Ashta, and Ashokrao Mane College of Pharmacy, Peth-Vadgaon, Kolhapur for providing facility to complete research.

\section{CONFLICT OF INTEREST}

The authors declare no conflict of interest.

\section{ABBREVIATIONS}

FTIR: Fourier Transform Infrared Spectroscopy; PDE: Percent drug entrapment; SPC: Soya phosphatidyl choline; CH: Cholesterol; TEM: Transmission Electron
Microscopy; DSC: Differential scanning calorimetry; HCL: Hydrochloric acid.

\section{REFERENCES}

1. Davoudi ET, Noordin MI, Farjam AS, Javar HA. Preparation and Characterization of a Gastric Floating Dosage Form of Capecitabine. Bio Med Res Int. 2013;2013:495319.

2. Padamawar MN, Pokharkar VB. Development of vitamin loaded topical formulation using factorial liposomal formulation, drug deposition and stability. Int J Pharm. 2006;320(1-2):37-44.

3. Jain NK. Advances in controlled and novel drug delivery. $1^{\text {st }}$ edition, CBS Publishers. 1997;304-52.

4. Bangham AD, Standish MM, Watkines JC. Diffusion of univalent across the lamella of swollen phospholipids. J Mol Biol. 1965;13(1):238-52.

5. Vyas SP, Khar RK. Targeted and controlled drug delivery. $1^{\text {st }}$ edition, CBS Publishers. 2002.

6. Qingguo XU, Yasuhiro T, Jan TC. Encapsulation and release of a hydrophobic drug from hydroxyapatite coated liposomes. Biomaterials. 2007;28(16):268794.

7. Daraee H, Etemadi A, Kouhi M, Alimirzalu S, Akbarzadeh A. Application of liposomes in medicine and drug delivery. Artif Cells Nanomed Biotechnol. 2016;44(1):381-91.

8. Ong SG, Ming LC, Lee KS, Yuen KH. Influence of the Encapsulation Efficiency and Size of Liposome on the Oral Bioavailability of GriseofulvinLoaded Liposomes. Pharmaceutics. 2016;8(3):25.

9. Gabizon A, Goren D, Cohen R, Barenholz Y. Development of liposomal anthracyclines: From basics to clinical applications. J Control Release. 1998;53(1-3):275-9.

10. Akbarzadeh A, Sadabady R, Davaran S, Joo S, Zarghami N, Hanifrehpour Y. et al. Liposome: Classification, preparation and application. Nanoscale Res Lett. 2013;1-9.

11. Bozzuto G, Molinari A. Liposomes as nanomedical devices. Intl J Nanomedicine. 2015;10:975-99.

12. Shimma N, Umeda I, Arasaki M, Murasaki C, Masubuchi K, Kohchi Y, et al. The design and synthesis of a new tumor-selective fluoropyrimidinecarbamate, capecitabine. Bioorg Med Chem. 2000;8(7):1697-706.

13. Wang MLH, Yung WKA, Royce ME, Schomer DF, Theriault RL, Wogan CF. Capecitabine for 5-fluorouracil-resistant brain metastases from breast cancer. Am J Clin Oncol. 2001;24(4):421-4.

14. Reigner B, Blesch K, Weidekamm E. Clinical Pharmacokinetics of Capecitabine. Clin Pharmacokinet. 2001;40(2):85-104.

15. Walko CM, Lindley C. Review on Capecitabine. Clin Ther. 2005;27(1):23-44.

16. Honmane S, Salunkhe S, Hajare A, Bhatia N, Mali S. Comparative efficiency of formulation technique for development of salbutamol sulphate loaded liposome. Int Res J Pharm. 2014;5(2):70-4.

17. Ranga S, Jaimini M, Sharma SK, Chauhan BS. A review on the design of experiments (DE). Int J Pharm Chem Sci. 2014;3:216-24.

18. Rathod S, Deshpande SG. Design and evaluation of liposomal formulation of pilocarpine nitrate. Indian J Pharm Sci. 2010;72(2):155-60.

19. Venugopalarao G, Lakshmipathy $R$, Sarada N. Preparation and characterization of cefditoren pivoxil-loaded liposomes for controlled in vitro and in vivo drug release. Intl J Nanomedicine. 2015;10(Suppl 1):149-57.

20. Patel SS, Patel SM, Salampure S, Vishwanath B, Patel NM. Development and evaluation of liposome for topical delivery of tacrolimus. J Sci Res. 2010;2(3):585-96.

21. Song J, Shi F, Zhang Z, Zhu F, Xue J, Tan X, et al. Formulation and evaluation of celastrol-loaded liposomes. Molecules. 2011;16(9):7880-92.

22. Nagarsenker M, Londhe VY, Nadkarni G. Preparation and evaluation of liposomal formulations of tropicamide for ocular delivery. Int $\mathrm{J}$ Pharm. 1999;190(1):63-71.

23. Hathout R, Mansour S, Mortada N, Guinedi A. Liposomes an ocular delivery system for acetazolamide: in-vitro and in-vivo studies. Aaps Pharmscitech. 2007;8(1):1-12. 
KM. Ciprofloxacin as ocular liposomal hydrogel. AAPS Pharm Sci Tech. 2010;11(1):241-6.

25. Panwar P, Pandey B, Lakhera PC, Singh KP. Preparation, characterization and in vitro release study of albendazole-encapsulated nanosize liposomes. Int J Nanomedicine. 2010;5:101-8.

26. Honmane S, Hajare A, More H, Osmani R, Salunkhe S. Lung delivery of nanoliposomal salbutamol sulphate dry powder inhalation for facilitated asthma therapy. J Liposome Res. 2019;23:111. doi: $10.1080 / 08982104.2018 .1531022$
27. Dash S, Murthy P, Nath L, Chowdhury P. Kinetic Modeling on Drug Release from Controlled Drug Delivery Systems. Acta Pol Pharm. 2010;67(3):217-23.

28. Cojocaru V, Ranetti A, Hinescu L, Ionescu M, Cosmescu C, Postoarca A, et al. Formulation and Evaluation of in vitro Release Kinetics of $\mathrm{Na}_{3} \mathrm{ca}$ DTPA DE corporation Agent Embedded in Micro emulsion-Based Gel Formulation for Topical Delivery. Farmacia. 2015;63(5):656-64

29. Muppidi K, Pumerantz A, Wang J, Betageri G. Development and Stability Studies of Novel Liposomal Vancomycin Formulations. ISRN Pharmaceutics. 2012;1-8

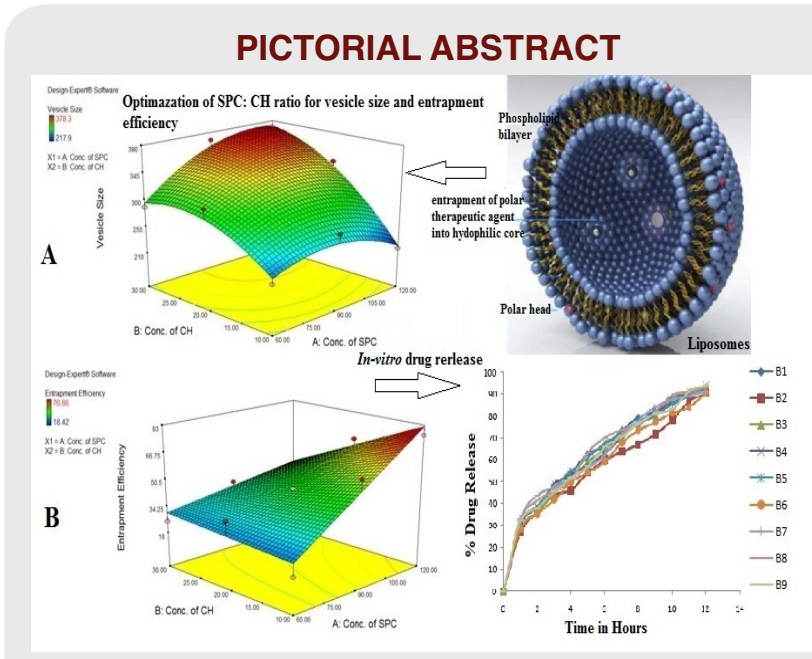

\section{PICTORIAL ABSTRACT}

- Capecitabine liposomal formulation was optimized using $3^{2}$ factorial design in this amount of soya Phosphatidylcholine and cholesterol were selected as two independent variables to obtaining stable liposome with small vesicle size and maximum entrapment efficiency.

- Liposomal drug delivery is targeted so it provides more drug concentration at site of action and with sustainable drug release followed higuchi-matrix model. Ultimately reducing the dosing frequency with minimizing the side effects related to high drug intake. Liposomal drug delivery has a great promise in the future.

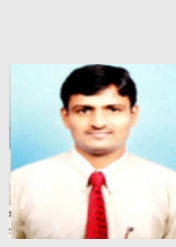

About Authors

Mr. Sandip M. Honmane, M. Pharm. in Pharmaceutics and pursuing Ph.D. in Pharmaceutical Sciences from Shivaji University, Kolhapur. He worked with Cipla Ltd., Goa. He has total more than 6 years of experience in Pharma profession. He has 3 years of experience in pharmaceutical industry, Cipla Ltd., Goa with exposure of solid, semisolid and injectable dosage forms. He has expert hand on validation and qualification of process and product. He had actively involved and faced different regulatory audits like WHO, MHRA, TGA, MCC and USFDA. He has published more than 10 research papers in national and international journals and two book publications on his credit. He is currently working as Assistant Professor at Annasaheb Dange College of B. Pharmacy, Ashta (MS).

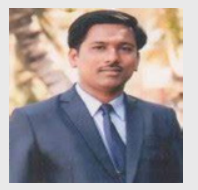

Mr. Sandip A. Bandgar, M. Pharm. in Biopharmaceutics and pursuing Ph.D. in Pharmaceutical Sciences from Shivaji University, Kolhapur. Currently working as Assistant Professor at Ashokrao Mane College of Pharmacy, Peth-Vadgaon, Kolhapur (MS). He had 11 years of teaching experience. $\mathrm{He}$ is Approved PG Teacher. He has $>15$ International and national Publications. He is a Life member of various professional associations like IPA, APTI \& IPS.

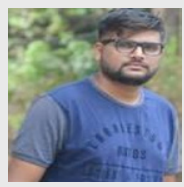

Mr. Sagar M. Chimane, has completed M. Pharm. in Pharmaceutics from Ashokrao Mane College of Pharmacy, Peth-Vadgaon, Kolhapur (MS), Currently working as Quality Assurance Officer at Encube Ethicals Pvt. Ltd in Ponda, Goa.

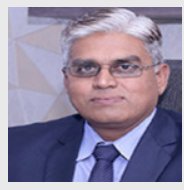

Dr. Shitalkumar S. Patil, M.Pharm. Ph.D. Professor and Principal at Ashokrao Mane College of Pharmacy, Peth-Vadgaon, Kolhapur (MS). He had more than 25 years of teaching experience. He is Approved PG Teacher and Ph.D Guide. He has > 40 International and national Publications. He is a Life member of various professional associations like IPA, APTI and IPS.

Cite this article: Honmane SM, Chimane SM, Bandgar SA, Patil SS. Development and Optimization of Capecitabine loaded Nanoliposomal System for Cancer Delivery. Indian J of Pharmaceutical Education and Research. 2020;54(2):376-84. 